\title{
Evaluation of high-risk type 1 diabetes HLA-DR and DQ haplotypes using three single nucleotide polymorphisms in a population from Southern Brazil
}

\author{
Guilherme Coutinho Kullmann Duarte*, Tais Silveira Assmann, Égina Marina Barbosa Martins, \\ Mariana Lopes dos Santos, Luis Henrique Canani, Daisy Crispim
}

From 20th Brazilian Diabetes Society Congress

Porto Alegre, Brazil. 11-18 November 2015

\section{Background}

Type 1 diabetes mellitus (T1D) accounts for $\sim 10 \%$ of all diabetes cases, and it is caused by autoimmune destruction of pancreatic beta-cells, which leads to insulin deficiency and fates individuals to require insulin treatment to survive. The triggering of autoimmunity against betacells is caused by interaction between environmental and genetic risk factors. Among the several loci associated with T1D, the human leukocyte antigen (HLA) class II DR/DQ locus is the main genetic risk factor for T1D, accounting for $30-50 \%$ of genetic risk for this disease. Other genes have been associated with minor effects on T1D risk when compared with HLA, with different studies indicating that the effect of non-HLA polymorphisms on predisposition for T1D may be different according to HLA DR/DQ types. In this scenario, a recent study identified a minimum set of three polymorphisms (rs3104413, rs2854275, rs9273363) which can predict high-risk HLA-DR/DQ types relevant to T1D.

\section{Objective}

To evaluate frequencies of high-risk T1D HLA-DR/DQ haplotypes in a Southern Brazilian population using a minimum set of HLA polymorphisms (rs3104413C/G, rs2854275A/C and rs9273363A/C).

\section{Materials and methods}

We analyzed 387 T1D patients (cases) and 375 healthy blood-donor subjects (controls). The local ethics committee approved the protocol, and all patients signed an informed consent form. Polymorphisms of interest were genotyped by allelic discrimination - RT-PCR technique using TaqMan MGB probes (Life Technologies). Haplotype combinations of the three analyzed polymorphisms were used for defining the HLA types relevant to T1D (Nguyen et $\mathrm{al}^{*}$ ), distinguishing the highest-risk DR4DQ8 and DR3/4-DQ types.

\section{Results}

Minor alleles frequencies of rs3104413, rs2854275, rs9273363 were increased in T1D patients as compared to non-diabetic subjects (rs3104413C: $44.4 \%$ vs. $11.2 \%$; rs2854275A: $12.9 \%$ vs. $1.9 \%$; rs9273363A: $43.9 \%$ vs. $9.9 \%$; all $\mathrm{P}<0.0001$ ). The frequency of high-risk DR4-DQ8 type was $66.7 \%$ in T1D cases and $15.3 \%$ in controls (OR=11.059, 95\%CI 6.68-18.29; $\mathrm{P}<0.0001)$. The high-risk DR3/4-DQ8 heterozygous haplotype was observed in only one T1D patients and in none control subject.

\section{Conclusion}

As expected, the high-risk HLA-DR4/DQ8 haplotype is associated with increased risk for T1D in our population. The genetic risk of non-HLA genes on T1D in Southern Brazil can now be correct for different high-risk HLA-DR/ DQ types.

\footnotetext{
* Correspondence: gui_couto@hotmail.com

Hospital de Clínicas de Porto Alegre, Porto Alegre, Brazil
} 


\section{Reference}

1. Nguyen, et al: Diabetes 2013, 62:2135-40.

doi:10.1186/1758-5996-7-S1-A215

Cite this article as: Duarte et al:: Evaluation of high-risk type 1 diabetes HLA-DR and DQ haplotypes using three single nucleotide

polymorphisms in a population from Southern Brazil. Diabetology \&

Metabolic Syndrome 2015 7(Suppl 1):A215.

Submit your next manuscript to BioMed Central and take full advantage of:

- Convenient online submission

- Thorough peer review

- No space constraints or color figure charges

- Immediate publication on acceptance

- Inclusion in PubMed, CAS, Scopus and Google Scholar

- Research which is freely available for redistribution

Submit your manuscript at 